\title{
Effects of Altered Amygdalar Neuropeptide Y Expression on Anxiety-Related Behaviors
}

\author{
Stefany D Primeaux*, ${ }^{*}$, , Steven P Wilson', Michael C Cusick ${ }^{2}$, David A York ${ }^{2}$ and Marlene A Wilson' \\ 'Department of Pharmacology, Physiology \& Neuroscience, University of South Carolina School of Medicine, Columbia, SC, USA; ${ }^{2}$ Experimental \\ Obesity, Pennington Biomedical Research Center, Baton Rouge, LA, USA
}

\begin{abstract}
Neuropeptide Y (NPY) decreases anxiety-related behaviors in various animal models of anxiety. The purpose of the present study was to examine the role of the amygdalar NPY system in anxiety-related responses in the elevated plus maze. The first experiment determined if herpes virus-mediated alterations in amygdalar NPY levels would alter anxiety-related behaviors in the elevated plus maze. Viral vectors encoding NPY, NPY antisense, or LacZ (control virus) were bilaterally injected into the amygdala, and 4 days postinjection, rats were tested in the elevated plus maze test. NPY-like immunoreactivity (NPY-ir) was measured in the amygdala of these rats. In rats injected with the viral vector encoding NPY, reduced anxiety-related behaviors in the elevated plus maze accompanied by moderate increases in NPY-ir were detected compared to NPY-antisense viral vector-treated subjects. Elevated plus maze behavior did not differ compared to LacZ-treated controls. NPY overexpression at this time point was also suggested by enhanced NPY mRNA expression seen in the amygdala 4 days postinjection using real-time polymerase chain reaction analysis. Experiment 2 was conducted to provide further evidence for a role of amygdalar NPY in regulating anxiety-related behaviors in the elevated plus maze test. The nonpeptide NPY YI receptor antagonist, BIBP $3226(\mid .5 \mu \mathrm{g} / \mu \mathrm{l})$, was bilaterally injected into the amygdala and rats were tested in the elevated plus maze test. Rats receiving BIBP 3226 exhibited increased anxiety-related behaviors in this test. The results of these experiments provide further support for the role of amygdalar NPY in anxiety-related behaviors.

Neuropsychopharmacology (2005) 30, 1589-1597. doi:I0.1038/sj.npp. I 300705; published online 16 March 2005
\end{abstract}

Keywords: neuropeptide Y; anxiety; viral vectors; amygdala; elevated plus maze; BIBP 3226

\section{INTRODUCTION}

Neuropeptide Y (NPY), a 36-amino-acid peptide, is one of the most abundant peptides in the central nervous system. This neuropeptide is found in cortical structures, the ventral and dorsal striatum, limbic structures, and brain stem, and is often colocalized with norepinephrine and gammaaminobutyric acid as well as other neuropeptides (Heilig and Widerlov, 1990; Kask et al, 2002). NPY plays a role in anxiety (Britton et al, 1997, 2000; Broqua et al, 1995; Heilig et al, 1993; Pich et al, 1993; Sajdyk et al, 1999), depression (Holmes et al, 1998; Jimenez-Vasquez et al, 2000, 2001; Primeaux and Holmes, 2000; Song et al, 1996; Stogner and Holmes, 2000; Widerlov et al, 1988), feeding (Daniels et al, 2001; Flood and Morley, 1991; Heilig et al, 1993; Mullins et al, 2001; Polidori et al, 2000), and seizure activity (Baraban et al, 1997; Erickson et al, 1996; Primeaux et al,

\footnotetext{
*Correspondence: Current address: Dr SD Primeaux, Experimental Obesity, Pennington Biomedical Research Center, 6400 Perkins Road, Baton Rouge, LA 70808, USA, Tel: + 225763 2559, Fax: + 225763 2525, E-mail: PrimeaSD@pbrc.edu

Received 28 May 2004; revised 20 December 2004; accepted 17 January 2005

Online publication: 26 January 2005 at http://www.acnp.org/citations/ NPPO I 260504250/default.pdf
}

2000; Vezzani et al, 2002; Weinshenker et al, 2001; Woldbye et al, 1996, 1997).

The role of NPY in anxiety-related behaviors has been investigated in a variety of behavioral tests. Intracerebroventricular (i.c.v.) administration of NPY or NPY Y1 receptor agonists decrease anxiety-related behaviors in the Geller-Seifter conflict test, fear potentiated startle test, and the elevated plus maze test, without altering locomotor activity. (Britton et al, 1997, 2000; Broqua et al, 1995; Heilig et al, 1989; Nakajima et al, 1998). In contrast, NPY Y2 receptor agonists decrease the percent time spent in the open arms of the plus maze, which is indicative of increased levels of anxiety (Nakajima et al, 1998). I.c.v. administration of antisense oligonucleotides for the NPY Y1 receptor and i.c.v. administration of the nonpeptide NPY Y1 receptor antagonist, BIBP 3226, increase anxiety-related behaviors in the elevated plus maze test (Kask et al, 1996; Wahlestedt et al, 1993). NPY knockout mice also show increased anxiety-related behaviors in the open-field test and the acoustic startle test (Bannon et al, 2000).

The amygdala plays a critical role in fear- and anxietyrelated behaviors (Davis et al, 1997; LeDoux, 1992, 2000; Roozendaal et al, 1997; Wallace and Rosen, 2001). Several lines of evidence suggest that the anxiolytic-like effects of NPY may be mediated through the central nucleus of the 
amygdala. The central nucleus of the amygdala receives a dense innervation of NPY from the nucleus of the solitary tract, arcuate nucleus, and lateral septum (Chronwall et al, 1985; Zardetto-Smith and Gray, 1990), and contains a moderate amount of NPY Y1 receptors, which are important for the anxiolytic effects of NPY (Wolak et al, 2003). Administration of NPY or an NPY Y1 agonist into the amygdala selectively increased punished responding in the Geller-Seifter conflict test (Heilig et al, 1993). In the elevated plus maze test, decreased open arm exploration, indicative of an anxiogenic effect, was found in rats receiving intra-amygdala antisense oligonucleotide injections to inhibit NPY Y1 receptor gene expression in that region (Heilig, 1995). The effects of intra-amygdala injections of the nonpeptide NPY Y1 receptor antagonist, BIBP 3226, have been examined in the elevated plus maze behavior, but no changes in anxiety-related behaviors were found (Kask et al, 1998).

In the current experiments, the effects of virally mediated increases and decreases in amygdalar NPY were investigated. Viral vectors are gaining widespread use as a method for gene transfer into the central nervous system (Kay et al, 2001). This technique is not only important for treating genetic disorders but can also be used to influence existing functions or produce new functions in the central nervous system (Carlezon et al, 2000a, b; Hermens and Verhaagen, 1998; Kaplitt and Makimura, 1997). Viral vectors may also serve to eliminate problems associated with exogenous administration of neuropeptides, which may be subject to time and temperature degradation (Taylor et al, 1990). Herpes simplex virus, type-1 (HSV) vectors encoding the neuropeptide enkephalin have been used successfully to alter nociception as well as benzodiazepine-induced anxiolysis in the elevated plus maze (Kang et al, 1998, 2000). In addition, HSV vectors encoding enkephalin have been used to alter depression-related symptoms in an animal model of depression (Primeaux et al, 2003). HSV vectors have been shown to be region specific and transient (Kang et al, 2000). HSV vectors have been shown to be region specific and transient (Kang et al, 2000). Owing to their short duration, HSV vectors should be less likely to significantly alter other amygdalar genes and induce receptor adaptations, as well as allow an analysis of the reversibility of the effects due to viral changes in expression (Carlezon et al, 2000b; Kang et al, 2000).

The purpose of the current work was to determine if altered NPY levels using an HSV expression vector into the amygdala would alter anxiety-related behaviors in the elevated plus maze. It was predicted that HSV-mediated increases in amygdalar NPY expression would decrease anxiety-related behaviors and HSV-mediated decreases in amygdalar NPY expression would increase anxiety-related behaviors in the elevated plus maze. Consequently, appropriate alterations in amygdalar NPY peptide levels should be detected and correlated to anxiety-related behaviors. Additionally, the nonpeptide NPY Y1 receptor antagonist, BIBP 3226, was injected into the amygdala of naive rats to provide further evidence for the role of amygdalar NPY and NPY Y1 receptors in anxiety-related behaviors. It was predicted that BIBP 3226 would increase anxiety-related behaviors in the elevated plus maze test.

\section{METHODS}

\section{Experiment 1: Effects of Altered Amygdalar NPY Expression on Anxiety-Related Behaviors and Verification of Viral Expression}

Subjects. Adult Long-Evans male rats (Harlan, Indianapolis, IN) weighing $175-200 \mathrm{~g}$ at the time of arrival were used in this experiment. Rats were individually housed on a $12: 12$ light/dark cycle (lights on at 0700) with food/water available ad libitum. For elevated plus maze testing in Experiment 1, eight to 10 rats per group were used. For real-time polymerase chain reaction (PCR), separate groups were used with two to five rats per group. For Experiment 2, eight to nine rats per group were used. All procedures were approved by either the University of South Carolina or Pennington Biomedical Research Center Institutional Animal Care and Use Committees, and followed the Principles for Care and Use of Laboratory Animals. Both facilities are accredited by the Association for the Assessment and Accreditation of Laboratory Animal Care (AAALAC).

Virus construction. Replication-defective, recombinant herpes viruses were created using the KOS strain of HSV with both copies of ICP4 (IE3) deleted (DeLuca et al, 1985). For overexpression of NPY, a shuttle plasmid, pUCNPY, was created to insert an expression cassette into the viral thymidine kinase gene. An expression cassette from $p C M V \beta$ (MacGregor and Caskey, 1989) containing the human cytomegalovirus immediate-early promoter enhancer, the Escherichia coli lacZ gene, and the SV40 polyadenylation site was cloned into the SnaBI site of pUCX1 (contains the 'BamP' fragment of HSV; generously provided by JC Glorioso, University of Pittsburgh). After removal of the lacZ gene, the human NPY cDNA from pBShNPY (generously provided by RE Mains, Johns Hopkins University) was cloned into the plasmid. For generation of the virus DNPY, the linearized pUCNPY was transfected with PacIdigested viral DNA that contained a similar lacZ expression cassette flanked with PacI restriction sites (virus DPZ, method of Krisky et al, 1997) into the complementing 7B cell line (Marconi et al, 1996). Recombinant viruses were selected by three rounds of limiting dilution and the expected insertion into the virus confirmed by Southern blotting. Virus stocks were prepared using $7 \mathrm{~B}$ cells, concentrated by centrifugation, and were stored in MEM containing $10 \%$ cosmic calf serum (HyClone), $5 \mathrm{mM}$ HEPES, $\mathrm{pH} 7.4$, and $10 \%$ glycerol. A diagram of the final viral construct is illustrated in Figure 1. A recombinant virus containing the full-length human NPY cDNA in antisense orientation relative to the promoter (virus DANPY) was similarly constructed (see Figure 1).

HSV-mediated gene transfer surgery. At 1 week following arrival, rats were anesthetized with a combination of sodium pentobarbitol (Nembutal, $25 \mathrm{mg} / \mathrm{kg}$, intraperitoneal (i.p.)) and ketamine hydrochloride $(40 \mathrm{mg} / \mathrm{kg}$, i.p.). Rats were placed in a stereotaxic apparatus (David Kopf, Tujunga, CA), a midline incision was made, and bregma was measured from the skull surface. Bilateral injections of the replication-deficient HSV encoding either human prepro-NPY (DNPY, $\left.2.0 \times 10^{6} \mathrm{PFU} / \mu \mathrm{l}\right)$, NPY antisense 


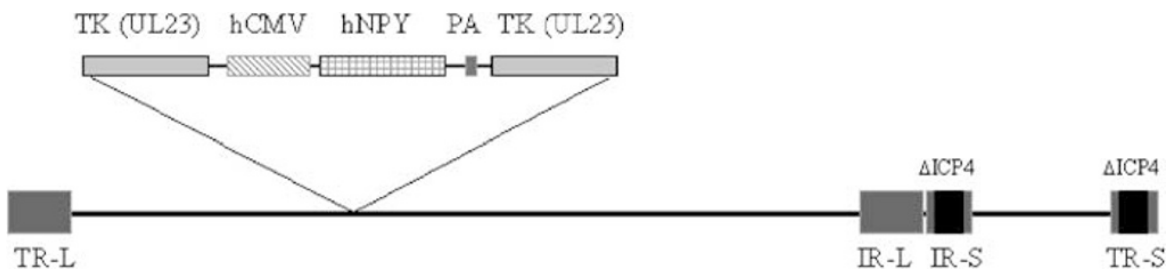

Figure I Schematic diagram of the HSV constructs used in this study. Viruses were constructed using the human prepro-NPY cDNA inserted in the sense orientation relative to the CMV promotor (virus DNPY) or in the antisense orientation (virus DANPY). A similar virus encoding the product of the lacZ gene, $\beta$-galactosidase (virus DPZ) was employed as a control. See Methods for construction details and abbreviations.

(DANPY, $\left.2.0 \times 10^{6} \mathrm{PFU} / \mu \mathrm{l}\right)$, or lac $Z\left(\mathrm{DPZ}, 2.0 \times 10^{6} \mathrm{PFU} / \mu \mathrm{l}\right)$ were made through two holes drilled into the rat's skull. Injections were made with a $26-\mathrm{G}$ Hamilton syringe and aimed at the amygdala (AP $-2.0, \mathrm{LM} \pm 4.6$, and $\mathrm{DV}-8.7$ from skull; Paxinos and Watson, 1997). Injections were made at a rate of $0.2 \mu \mathrm{l} / \mathrm{min}$ ( $1 \mu \mathrm{l}$ total volume) using a motorized injector (Micro 4, Microsyringe Pump Controller, World Precision Instruments) followed by a $10 \mathrm{~min}$ period in which the virus was allowed to diffuse prior to the needle being withdrawn. Following surgery, an injection of nalbuphine (Sigma, $1 \mathrm{mg} / \mathrm{kg}$, subcutaneously (s.c.)) was given for postoperative analgesia.

Real-time PCR. Analysis of amygdalar NPY gene expression was conducted following HSV-mediated NPY gene transfer surgery using real-time PCR. Unilateral injections of virus encoding either NPY or Anti-NPY were compared with unilateral injections of control ( $L a c Z$ ) viral constructs in the same brain (see above for surgical methods). RNA from crudely dissected amygdalas at 2, 4, 6, and 8 days postinjection was isolated using RNAqueous procedures (Ambion, Austin, TX, USA) and described in Primeaux et al (2003). Briefly, fresh tissue was homogenized in lysis buffer using a motorized tissue homogenizer (Tekmar, Cincinnati, $\mathrm{OH}$, USA), aqueous ethanol was added to lysate, and mixture was filtered through a vacuum manifold apparatus. Following several washes, the samples were subjected to an elution step, a lithium chloride precipitation procedure, and an ethanol wash. Remaining pellets were reconstituted with RNAase-free water. Reverse transcriptase (RT) was conducted using M-MLV procedures (Promega, Madison, WI, USA). For RT, $2 \mu \mathrm{g}$ of RNA from each sample was added to random primers (Promega) and incubated in a thermal cycler (PTC-100, MJ Research Inc., Watertown, MA, USA) for $5 \mathrm{~min}$ at $70^{\circ} \mathrm{C}$. Tubes were removed, placed on ice, and a mixture of $5 \times \mathrm{M}-\mathrm{MLV}, 10 \mathrm{mM} \mathrm{dNTP}$, and RT buffer was added. Tubes were returned to the thermal cycler for $60 \mathrm{~min}$ at $37^{\circ} \mathrm{C}$ and then $15 \mathrm{~min}$ at $70^{\circ} \mathrm{C}$. Real-time $\mathrm{PCR}$ was conducted with primers selective for both human and rat NPY, since the viral vector encodes human NPY. Primers were designed using Primer Express (Applied Biosystems, Foster City, CA, USA). The following primers were used for NPY: $5^{\prime}$-CCGCTCTGCGACACTACATC- $3^{\prime}$ and $5^{\prime}$-AAT CAGTGTCTCAGGGCTGGAT- $3^{\prime}$ (73 bp product) and for 18S: $5^{\prime}$-AGTCCCTGCCCTTGTACACA-3' ${ }^{\prime}$ and $5^{\prime}$-GATCC GAGGGCCTCACTAAAC-3' (69 bp product). For real-time PCR, SYBR Green $2 \times$ Master Mix (Applied Biosystems), forward and reverse primers $(10 \mu \mathrm{M})$, and RT product (10 ng) were added to 96 -well plates. The cycling parameters consisted of an initial $2 \mathrm{~min}$ incubation at $50^{\circ} \mathrm{C}$, followed by
$10 \mathrm{~min}$ at $95^{\circ} \mathrm{C}$, then $15 \mathrm{~s}$ at $95^{\circ} \mathrm{C}$, and a 1 min annealing step at $60^{\circ} \mathrm{C}$ ( 40 cycles $)$. A dissociation step $\left(15 \mathrm{~s}\right.$ at $\left.95^{\circ} \mathrm{C}\right)$ was added following 40 cycles to determine specificity of primers. Quantity of NPY mRNA was based on a standard curve and normalized to $18 \mathrm{~S}$ rRNA (ABI Prism 7900 Sequence Detection System, Applied Biosystems). Expression of NPY mRNA was assessed in 2-5 rats/group.

Elevated plus maze test. The elevated plus maze apparatus was made of either black Plexiglas or wood, consisted of two open $\left(56 \times 10 \times 0 \mathrm{~cm}^{3}\right)$ and two closed arms $\left(56 \times 10 \times 40 \mathrm{~cm}^{3}\right)$, and was elevated $50 \mathrm{~cm}$ above the floor. At 4 days following virally mediated gene transfer surgery or 1 week following bilateral cannulae implantation (Experiment 2), rats were brought into the behavioral testing room and immediately placed in the center of the elevated plus maze and videotaped for $5 \mathrm{~min}$. Following testing, rats were removed, returned to their home cage, and the maze was cleaned with a $10 \%$ chlorine bleach solution. Testing order was randomly determined to reduce time of day effects. An experimenter blind to experimental condition measured time spent in open and closed arms and entries into open and closed arms. The rat was considered in the open or closed arm, when all four paws had entered that arm. The percent time spent in open arms ((time in open arm/time in open + closed arm $) \times 100)$ and percent entries into open arms ((entries into open arms/total entries) $\times 100$ ) were used as measures of anxiety, and the number of total arm entries and closed arm entries were used as a measure of spontaneous locomotor activity. The amount of time between virus injection and behavioral testing was based on previous research using HSV viral vectors encoding proenkephalin, which found significant alterations in behavior 3-4 days postinjection (Kang et al, 2000; Primeaux et al, 2003).

Radioimmunoassay (RIA) of NPY. Rats were killed by rapid decapitation $30 \mathrm{~min}$ following elevated plus maze testing. Brains were removed, frozen on dry ice, and stored at $-80^{\circ} \mathrm{C}$. For dissection of the amygdala and the paraventricular nucleus of the hypothalamus (PVN), $1 \mathrm{~mm}$ slices from each brain were cut on a freezing microtome (Microm) based on the brain atlas of Palkovits and Brownstein (1988) and beginning on Plate 25 ( -1.8 from Bregma). Bilateral $2 \mathrm{~mm}$ punches were taken surrounding the central nucleus of the amygdala, and bilateral $1 \mathrm{~mm}$ punches were taken from PVN. Punches were weighed and stored at $-80^{\circ} \mathrm{C}$. Placements of punches were verified by staining the brain slices with thionin $(0.1 \%)$ and comparing the punched areas with a rat brain atlas (Paxinos and 
Watson, 1997). Improper bilateral placement of punches led to the removal of those animals from RIA data analyses. Brain samples were thawed on ice and $550 \mu \mathrm{l}$ of $2 \mathrm{~N}$ acetic acid was added to each tube. Samples were boiled on a heat block (Fisher Scientific) for $15 \mathrm{~min}$ at $100^{\circ} \mathrm{C}$ and then homogenized by sonication for $30 \mathrm{~s}$. The samples were centrifuged (Eppendorf, Centrifuge 5403) at $14000 \mathrm{rpm}$ for $5 \mathrm{~min}$ at $25^{\circ} \mathrm{C}$ and three $150 \mu \mathrm{l}$ aliquots were placed in polystyrene tubes. Samples were evaporated to dryness in a Labconco Centrivap concentrator and stored at $4{ }^{\circ} \mathrm{C}$. An RIA kit (Peninsula Laboratories Inc., Belmont, CA) was used to assess the levels of NPY as described in Primeaux and Holmes (2000). Each tube containing extracted peptide from the experimental/control tissue was reconstituted with $100 \mu \mathrm{l}$ of RIA buffer. Tubes for determining a standard curve (1-128 pg), nonspecific binding, total binding, and total count were included in each assay. On the third day of the RIA procedure, the remaining pellets were counted in a gamma counter to determine the levels of ${ }^{125} \mathrm{I}$. Levels of NPY-like immunoreactivity (NPY-ir) were determined from the standard curve after log-logit transformation of the data and results were expressed as ng NPY-ir/mg tissue weight.

\section{Experiment 2: Effects of the NPY-Y1 Receptor Antagonist, BIBP 3226, on Anxiety-Related Behaviors}

Bilateral indwelling cannula surgery. At 2 weeks following arrival to the Pennington Biomedical Research Center, rats underwent surgery to implant bilateral indwelling cannulae into the amygdala. Rats were anesthetized with sodium pentobarbital (Nembutal, $70 \mathrm{mg} / \mathrm{kg}$, i.p.) and placed in a stereotaxic apparatus (David Kopf, Tujunga, CA). A midline incision was made and bregma was measured from the skull surface. Bilateral 25-G stainless-steel cannulae, $12 \mathrm{~mm}$ in length were implanted with orthodontic resin (Dentsply Caulk, Milford, DE) into the amygdala, using the coordinates AP -2.0, LM \pm 4.6 , and DV -6.7 (Paxinos and Watson, 1997). Following surgery, an injection of nalbuphine (Sigma, $1 \mathrm{mg} / \mathrm{kg}$, s.c.) was given for postoperative analgesia.

Drug treatment. The selective, nonpeptide NPY Y1 antagonist, BIBP 3226 (Sigma-Aldrich, St Louis, MO), was dissolved in $0.9 \%$ sterile saline. On the day of behavioral testing, rats were injected bilaterally with $1 \mu$ l of BIBP 3226 $(1.5 \mu \mathrm{g} / \mu \mathrm{l})$ or sterile saline using a $31-\mathrm{G}$ injector, which extended $2 \mathrm{~mm}$ past the guide cannula. Injections were made with an infusion pump (Harvard Apparatus, Holliston, MA) at a rate of $0.5 \mu \mathrm{l} / \mathrm{min}$ for a total of $2 \mathrm{~min}$. The injectors remained in the cannulae for an additional minute. Rats were tested on the elevated plus maze $15 \mathrm{~min}$ following injections.

Histology. Rats were killed by rapid decapitation, and brains were removed and placed in $4 \%$ paraformaldehyde/ $0.1 \mathrm{M}$ sodium phosphate solution for $24 \mathrm{~h}$ at $4{ }^{\circ} \mathrm{C}$. After $24 \mathrm{~h}$, brains were removed and placed in a $15 \%$ sucrose $/ 0.1 \mathrm{M}$ sodium phosphate buffer at $4{ }^{\circ} \mathrm{C}$ until slicing. Brains were sliced (50 $\mu \mathrm{m}$ sections) using a cryostat (Leica), mounted on slides, and stained with cresyl violet histological stain. Brain slices were examined under a low-power microscope and amygdala cannulae placement was plotted using the rat brain atlas of Paxinos and Watson (1997). Three animals were removed from analyses due to improper cannulae placement.

Data analysis. One-way ANOVAs were performed for all behavioral measures in Experiment 1 and NPY-ir as detected by RIA. Bonferroni post-hoc analyses for viral construct were conducted if a main effect of viral construct was detected. Significance levels for all measures were set at $p<0.05$. Two rats were removed from all analyses due to improper injection placement. NPY mRNA expression as measured by real-time PCR was determined by a two-tailed $t$-test for each day postinjection. NPY mRNA expression levels were based on a standard curve and normalized to the $18 \mathrm{~S}$ rRNA housekeeping gene. The values determined from this normalization process were further normalized to the control (DPZ) side of the brain. This was carried out to eliminate the effects of differences between basal levels of amygdalar NPY gene expression. Two-tailed $t$-tests were performed for all behavioral measures in Experiment 2. The significance level for all measures was set at $p<0.05$.

\section{RESULTS}

\section{Real-Time PCR}

Real-time PCR indicated a significant increase in amygdalar NPY mRNA expression at 4 days following HSV-mediated gene transfer in rats receiving viral vectors encoding NPY as compared to rats receiving viral vectors encoding NPY antisense, $t(5)=5.03, p<0.01$. Data are represented as a ratio of NPY or NPY-antisense-treated side to the control (LacZ-treated) side (Figure 2). Rats receiving viral vectors encoding NPY, at 4 days, have an approximately two-fold increase in NPY mRNA levels from control (DPZ) levels. The ratio in NPY-antisense-treated amygdalas at 4 days were not significantly reduced from a ratio of one, suggesting that NPY mRNA expression in this group did not differ significantly from control (DPZ).

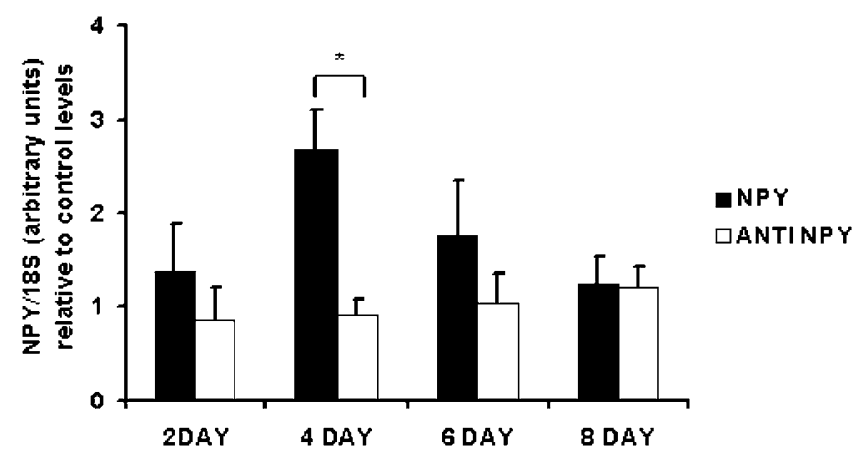

Figure 2 Virally mediated alterations in amygdalar NPY gene expression were measured by real-time PCR at four different time points. NPY gene expression was normalized to the housekeeping gene, I8S rRNA, and then normalized to the control side of the brain. At 4 days following intraamygdala injections of viral vectors encoding NPY (NPY) or NPY antisense (Anti-NPY), NPY gene expression was increased in rats receiving viral vectors encoding NPY as compared to those receiving viral vectors encoding for NPY antisense. Data are shown as mean \pm SEM, $n=2-5$ / group. $* p<0.05$ 
Experiment 1: Effects of Altered Amygdalar NPY Expression on Anxiety-Related Behaviors and Verification of Viral Expression

Elevated plus maze. As seen in Figure 3, a main effect of viral vector was seen in the percent time spent in the open arms of the plus maze $(\mathrm{F}(2,27)=5.55, p<0.01)$ and in the percentage of entries into the open arms of the plus maze $(F(2,27)=3.43, p<0.05)$, both indicators of anxiety-related behaviors. Bonferroni post hoc tests revealed that rats overexpressing amygdalar NPY (NPY vector) spent significantly more time in the open arms of the plus maze and made more entries into the open arms as compared to rats receiving the antisense NPY vector, suggesting decreased anxiety $(p<0.05)$. No differences were detected between control vector animals and NPY or antisense NPY groups on these measures. There were no differences between the groups on spontaneous locomotor activity as measured by closed arm entries $(p=0.56)$ or total arm entries $(p=0.10)$.

NPY is an orexigenic peptide, and therefore, body weight on testing day was compared to body weight prior to surgery. Body weight was not significantly different prior to surgery $(p>0.05)$. However, rats receiving amygdala injec-
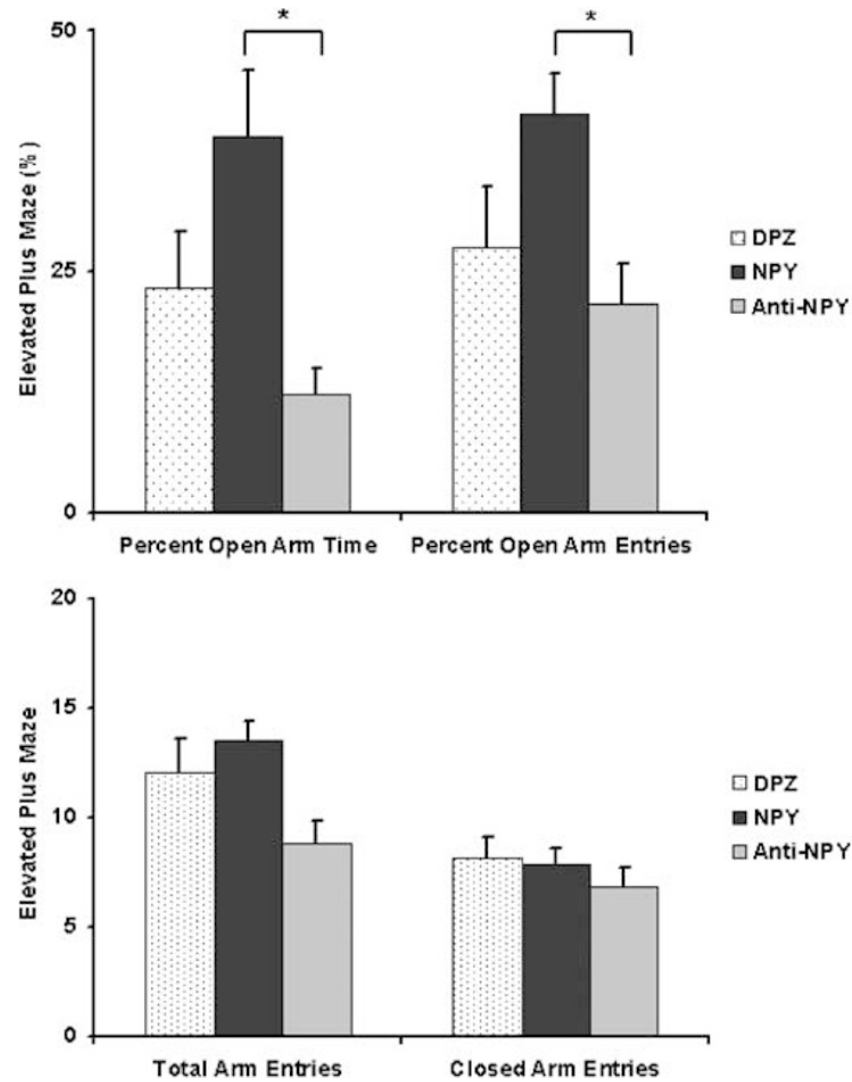

Figure 3 Anxiety and activity measures in the elevated plus maze test. The elevated plus maze test was used to examine the effects of HSVmediated alterations in amygdalar NPY. HSV viral vectors encoded human prepro-NPY (NPY), NPY antisense (Anti-NPY), or a control virus (DPZ). The percent time spent in the open arms and percent number of entries into the open arms was increased in rats overexpressing amygdalar NPY compared to rats with reduced expression of amygdalar NPY. No differences were seen in total arm entries or closed arm entries. Data are shown as mean $\pm \mathrm{SEM}, n=9$ - I0/group. ${ }^{*} p<0.05$. tions of viral vectors encoding NPY weighed significantly more than either NPY-antisense treated or control (DPZ) on testing day $(244 \mathrm{~g} \pm 4.9,225.1 \mathrm{~g} \pm 5.6,230.5 \mathrm{~g} \pm 3.8$, respectively), $\mathrm{F}(2,28)=4.33, p<0.03$.

Radioimmunoassay. Rats receiving injections of the HSV vector encoding NPY showed a moderate increase in amygdalar NPY-ir (ng/tissue weight) as compared to rats receiving injections of the HSV vector encoding NPY antisense $(\mathrm{F}(2,14)=2.49, p=0.11)$ as seen in Figure 4 . Following intra-amygdala injections of the virus encoding for human prepro-NPY, amygdala NPY-ir (mean \pm SEM; $18772.19 \pm 1735 \mathrm{ng} / \mathrm{mg}$ tissue) was moderately increased from control NPY levels, while NPY-ir was decreased from control NPY (mean \pm SEM; $16667.44 \pm 1168 \mathrm{ng} / \mathrm{mg}$ tissue) levels following intra-amygdala injections of the virus encoding NPY antisense (mean \pm SEM; $13962.2 \pm 1613 \mathrm{ng} /$ mg tissue). As expected, HSV vectors encoding either NPY or NPY antisense injected into the amygdala did not alter

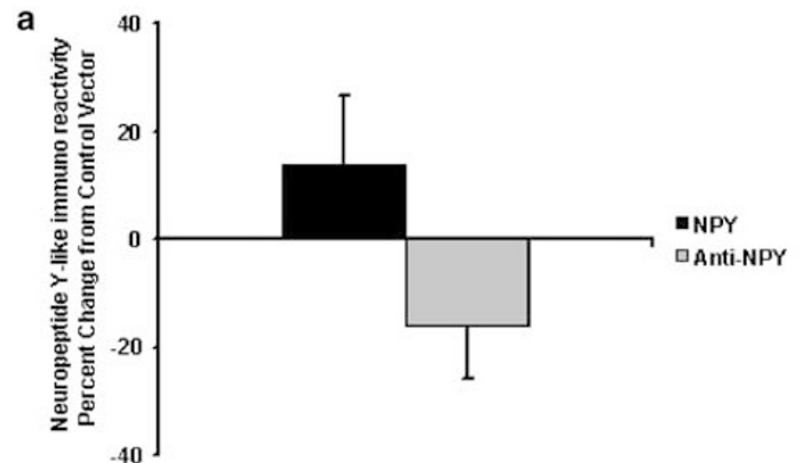

Amygdala

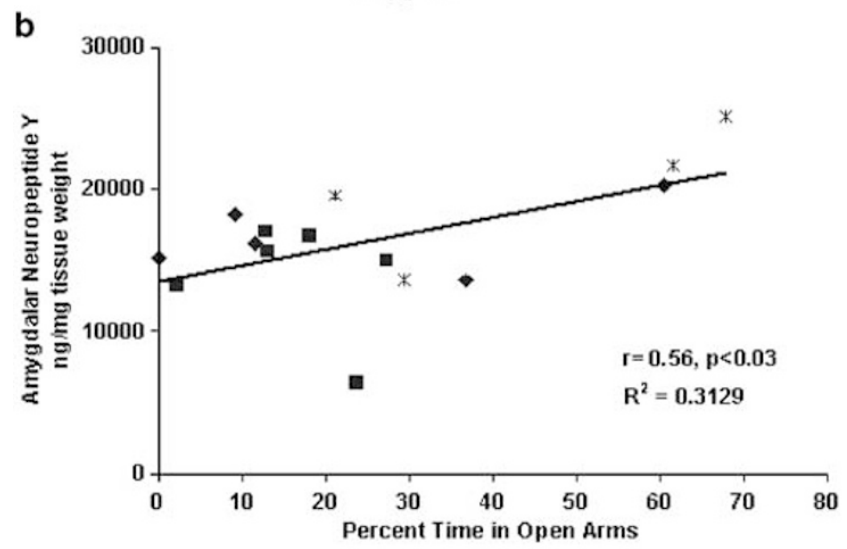

Figure 4 (a) NPY-ir was assessed following viral gene transfer in rats following elevated plus maze testing. Data are shown as a percentage of amygdalar NPY levels in rats receiving the control vector. Following intra-amygdala injections of the virus encoding for human prepro-NPY, amygdala NPY-ir (mean \pm SEM; $18772.19 \pm 1735 \mathrm{ng} / \mathrm{mg}$ tissue) was moderately increased from control NPY levels, while NPY-ir was decreased from control NPY (mean \pm SEM; $16667.44 \pm$ I 168 ng/mg tissue) levels following intra-amygdala injections of the virus encoding NPY antisense (mean \pm SEM; $13962.2 \pm 1613 \mathrm{ng} / \mathrm{mg}$ tissue). Data are shown as mean \pm SEM, $\bar{n}=4-6 /$ group for amygdala. (b) A correlational analysis was conducted to determine the relationship between amygdala NPY levels and anxiety in the elevated plus maze. A significant positive correlation was found between amygdala NPY levels and percent time spent in the open arms of the elevated plus maze. DPZ, Anti-NPY, * NPY. 
hypothalamic NPY-ir $(p=0.66)$, suggesting that alterations in HSV-mediated NPY gene expression are region specific. Correlational analyses were conducted to determine if amygdalar NPY levels (ng/tissue weight) were correlated with anxiety levels (percent open arm time). A significant positive relationship between amygdalar NPY levels and percent open arm time was found, $r=0.56, p<0.03$ (see Figure 4). Since several samples were removed from analysis due to inaccurate location of the punches, it is important to note that analyses were conducted only on animals that had both behavioral and neurochemical data available.

\section{Experiment 2: Effects of the NPY-Y1 Receptor Antagonist, BIBP 3226, on Anxiety-Related Behaviors}

Following BIBP 3226 or saline injections into the amygdala, rats were tested on the elevated plus maze. Intra-amygdala administration of the NPY Y1 receptor antagonist, BIBP 3226 , significantly decreased the percent time spent in the open arms of the plus maze $(t(12)=2.91, p<0.05)$ and the number of entries into the open arms of the plus maze $(t(12)=2.38, p<0.05)$, suggesting an increase in anxiety in rats receiving BIBP 3226 (see Figure 5). Neither total arm entries nor closed arm entries were altered by BIBP 3226 administration $(p>0.05)$.
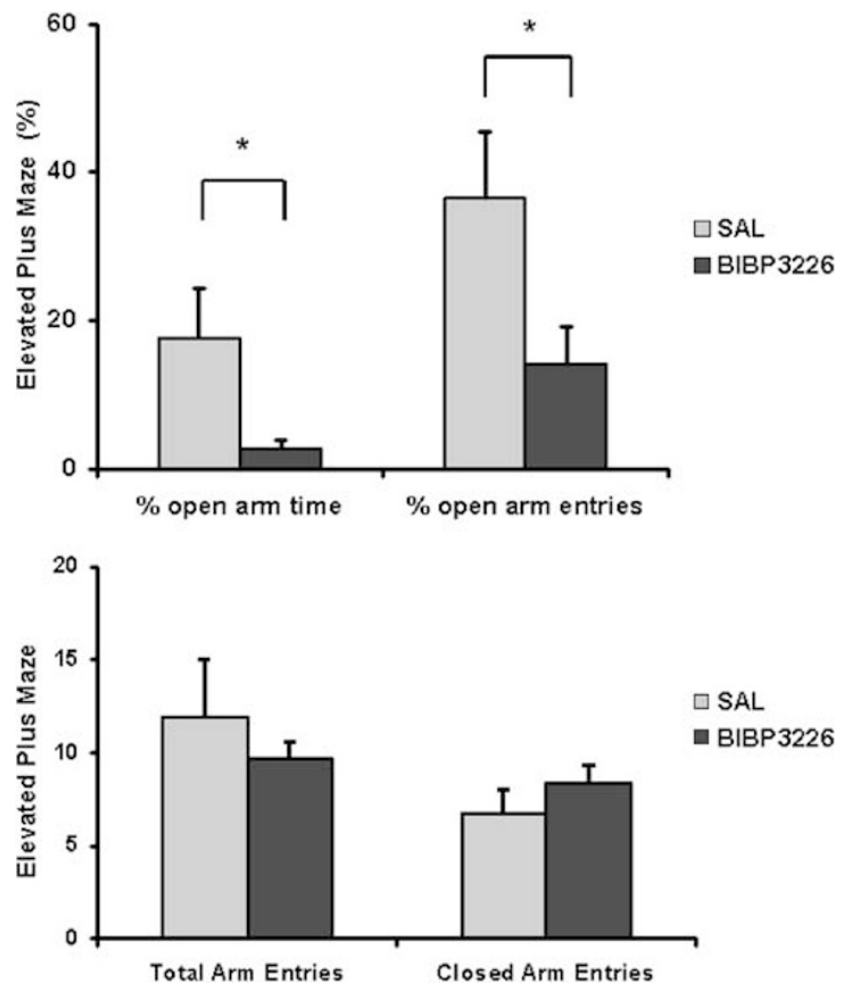

Figure 5 Anxiety and activity measures in the elevated plus maze test following intra-amygdala administration of the NPY YI receptor antagonist BIBP 3226. BIBP 3226 administration increased anxiety-related behaviors in this test as indicated by a decrease in the percent time spent in the open arms and percent number of entries into the open arms in this test. Locomotor activity was not altered as measured by the number of total arm entries and closed arm entries. Data are shown as mean \pm SEM, $n=5$-9/group. ${ }^{*} p<0.05$.

\section{DISCUSSION}

Experiment 1 was conducted to determine if HSV-mediated alterations in amygdalar NPY levels would alter anxietyrelated behaviors in the elevated plus maze test. This experiment provides evidence for virally mediated increases and decreases in amygdalar NPY peptide levels that are correlated with altered anxiety-related behaviors in the plus maze. Increases in amygdalar NPY gene expression through the use of real-time PCR were also seen in a separate group of animals. Virally mediated alterations of amygdalar NPY are region specific; viral constructs did not alter hypothalamic NPY levels. These factors provide strong evidence in support of the use of viral vectors as tools to alter behavior and neurochemistry. The anxiogenic effect of an NPY Y1 antagonist provides additional evidence for the role of amygdalar NPY and NPY Y1 receptors in anxiety-related behaviors (Experiment 2). The results from this experiment are congruent with previous evidence, indicating that NPY agonists decrease anxiety-related behaviors and NPY antisense administration increases anxiety-related behaviors.

In both experiments, the elevated plus maze test was used to assess anxiety-related behaviors. This test is a commonly used rodent model of anxiety and is susceptible to the anxiolytic effects of NPY. In the current experiment, HSVmediated increases in amygdalar NPY increased the percent time spent and the number of entries into the open arms of the plus maze, which are indicative of decreased levels of anxiety, while HSV-mediated decreases in amygdalar NPY decreased these indices of anxiety. HSV-mediated alterations in amygdalar NPY did not affect activity-related measures in this test, suggesting that the changes in anxiety seen following viral injections are due to changes in anxiety levels, not activity levels. Anxiety-related behaviors did not differ significantly between control vector animals and animals with HSV-mediated increases or decreases in amygdalar NPY. Although animals injected with sense and antisense vectors differed significantly in anxiety-related behaviors, neither group differed significantly from controlinjected animals. There are several possible reasons why this may have occurred. First, HSV-mediated overexpression may have increased amygdalar NPY gene expression and peptide levels, but NPY receptor populations may have been altered to accommodate for those increases; therefore, receptor numbers may act as a limiting factor for the behavioral effects of NPY. In addition, HSV vectors may affect multiple subregions of the amygdaloid complex, which have differing NPY receptor populations and functions. Overall, it is important to note that a significant positive correlation was found between amygdalar NPY levels and percent time spent in the open arms of the elevated plus maze, suggesting that even slight changes in amygdalar NPY gene expression and peptide levels are physiologically relevant. These results support the notion that amygdalar NPY may serve a subtle modulatory role in regulating anxiety-related behaviors in the plus maze. Experiment 1 investigated both the anxiolytic and anxiogenic effects of altered NPY expression; future experiments will examine these effects separately and will involve a preelevated plus maze stress to test the anxiolytic effects of HSV vectors overexpressing NPY and extensive handling 
procedures to examine the anxiogenic effects of HSV vectors underexpressing NPY.

Analysis of NPY mRNA expression using real-time PCR and NPY-ir using RIA suggested that injections of HSV vectors encoding prepro-NPY increased amygdala expression and release of NPY compared to levels seen with antisense NPY constructs. Amygdalar NPY gene expression, as determined by real-time PCR, was increased 4 days postinjection of HSV vectors encoding prepro-NPY. Rats receiving amygdala injections of HSV vectors encoding NPY antisense did not show significant decreases in NPY mRNA levels 4 days postinjection, as indicated by a ratio of 0.92 compared to the control vector (see Figure 2). The failure to observe significant reductions in NPY mRNA may reflect a relatively small number of cells transduced by the virus compared to the total number of NPY-containing neurons in the tissue sample analyzed. Changes in amygdalar NPY gene expression were not seen at 2,6 , or 8 days postinjection, although NPY levels appear to progressively increase up to 4 days and then begin to decline in the amygdala of NPY-treated rats. This is similar to previous evidence suggesting that HSV-mediated increases in amygdalar ENK gene expression are transient (Kang et al, 2000). Importantly, anxiety-related behaviors (ie percent time spent in the open arms of the plus maze) are significantly correlated with amygdalar NPY peptide levels (see Figure 4b) following HSV-mediated gene transfer.

Viral vectors encoding prepro-NPY increased NPY-ir in the amygdala and vectors encoding NPY antisense decreased NPY-ir in the amygdala. Alterations in hypothalamic NPY-ir were not detected, suggesting region specificity of the viral injections. A significant relationship was found between NPY-ir in the amygdala and anxiety measures in the elevated plus maze test. There are several explanations as to why the NPY-ir changes were not of the same magnitude as seen with mRNA expression. RIAs in micropunches assess NPY-ir in neurons and newly released peptides. Since rats were killed 30 min following testing, it is possible that a portion of the peptide was in the process of being degraded, thereby not providing an accurate picture of HSV-mediated changes in amygdala NPY levels. Another possibility is that the time course of HSV-mediated changes in amygdala NPY-ir is not highly correlated with HSVmediated changes in amygdala NPY gene expression, and either 4 days postinjection is not the most ideal time to measure NPY-ir following gene transfer surgery or the time course for antisense-induced decreases in peptide levels differs from that of overexpression. In addition, it is possible that the HSV technology adds a population of neurons that begin producing NPY, which may make overexpression techniques more effective in altering behavior and determining differences in neurochemistry. While this a potential caveat in utilizing viral vectors to overexpress a peptide, the results using local amygdala injections of the NPY Y1 receptor antagonist suggest that NPY release in the amygdala is involved in anxiety-related behaviors observed in the elevated plus maze test.

The nonpeptide NPY-Y1 receptor antagonist, BIBP 3226, increased anxiety-related behaviors in the elevated plus maze test. BIBP 3226 administration decreased the percent time spent and the number of entries into the open arms of the plus maze, without altering the number of total arm entries. These data suggest an overall increase in anxietyrelated behaviors without altering spontaneous locomotor activity. I.c.v. administration of BIBP 3226 has been shown to increase anxiety in the elevated plus maze test (Kask et al, 1996) and produce conditioned place aversions (Kask et al, 1999) without altering activity levels. BIBP 3226 injected into the periaquaductal gray also produces anxiogenic effects in the elevated plus maze; however, another study did not see changes in anxiety levels following BIBP 3226 injections into the amygdala, locus coereleus, or the PVN (Kask et al, 1998). The doses of BIBP 3226 for amygdala injections were comparable to the dose used in the current experiment $(0.5$ and $2.5 v s 1.5 \mu \mathrm{g} /$ side used in the current experiment). The finding in the current experiment that BIBP 3226 produced anxiogenic effects suggests that the two testing situations and/or procedures may have differed. Of particular significance may be the targeting of different amygdalar subnuclei. Our findings are further validated by previous evidence suggesting that intra-amygdalar administration of an NPY Y1 receptor agonist decreases anxietyrelated behaviors in the Geller-Seifter conflict test (Heilig et al, 1993) and administration of antisense oligonucleotides inhibits NPY Y1 receptor gene expression in the central nucleus of the amygdala decreases open arm exploration (increase anxiety) in the elevated plus maze test (Heilig, 1995).

The amygdala was chosen as the anatomical target in these experiments because the anxiolytic effects of NPY in the elevated plus maze are thought to be mediated through this region, specifically the central nucleus of the amygdala. It has been proposed that the central nucleus of the amygdala receives NPYergic innervation from the nucleus of the solitary tract, arcuate nucleus, and lateral septum (see Kask et al, 2002 for a review; Zardetto-Smith and Gray, 1990), and sends projections to the bed nucleus of the stria terminalis, which projects to the dorsal vagal complex and consequently may have effects on the autonomic nervous system (Allen et al, 1984, see Heilig and Widerlov, 1990 for a review). This circuitry may provide a partial explanation for the increased body weight seen in rats overexpressing amygdalar NPY. The PVN receives NPY input from the arcuate nucleus and is a brain region involved in NPYinduced increases in food intake (see Inui, 1999; Wilding, 2002 for a review). Although there are no known NPYergic pathways between the amygdala and the PVN (Gustafson et al, 1997), it is possible that NPY indirectly affects the release of one or more of the neuropeptides involved in food intake in the amygdala, bed nucleus of the stria terminalis, and/or the hypothalamus.

NPY Y1, Y2, and Y5 receptors and receptor mRNA are found in the amygdala (Gustafson et al, 1997; Parker and Herzog, 1999; Wolak et al, 2003) and each of these receptor subtypes has been implicated in anxiety (Kask et al, 2002). NPY Y2 receptors are thought to act presynaptically as autoreceptors providing negative feedback to NPYergic nerve terminals, while NPY Y1 receptors are thought to act postsynaptically (Kask et al, 2002; Wolak et al, 2003). NPY neurons in the amygdala project to the bed nucleus of the stria terminalis (Allen et al, 1984), which also contains NPY Y1 receptors and NPY Y1 and Y2 receptor mRNA (Gustafson et al, 1997; Parker and Herzog, 1999; Wolak et al, 2003). 
Experiment 1 provides strong support for the use of viral vectors as a method of altering gene expression and peptide levels in the rodent brain. The results from this experiment are in congruence with previous evidence that NPY agonists decrease anxiety-related behaviors and NPY antisense administration increases anxiety-related behaviors. Virally mediated increases in amygdalar NPY gene expression and peptide levels most likely reduce anxiety-related behaviors through NPY Y1 receptors found in the amygdala, which would suggest that the behavioral effects of HSV overexpression of NPY arise from a local circuitry; NPY is produced in the amygdala, released in the amygdala, and binds to NPY Y1 receptors in the amygdala. This is supported by the increase in both NPY peptide levels and NPY gene expression in the amygdala following HSVmediated overexpression of amygdalar NPY. This is also supported by the reduction in anxiety-related behaviors seen following the administration of the NPY Y1 antagonist, BIBP 3226, into the amygdala and by the reductions of both anxiety-related behaviors and NPY peptide levels in the amygdala following intra-amygdala administration of HSV encoding for NPY antisense. While this is the most parsimonious explanation of our results, it is also possible that viral gene transfer alters NPY mRNA expression in amygdala neurons, which send NPY projections to other brain sites such as the bed nucleus of the stria terminalis or periaquaductal gray, which contain NPY receptors, to subsequently modify behavior. Nevertheless, these studies implicate NPY systems in the amygdaloid complex as important for anxiety-related responses in this model. Unlike transgenic mice, which lack anatomical and developmental specificity, the use of viral vectors produces changes in both gene expression and peptide levels that act within a specific circuit and during a specific time frame to alter a measurable behavior. These factors make the use of viral vectors an extremely powerful tool for studying brain-behavior relationships.

\section{ACKNOWLEDGEMENTS}

We would like to acknowledge JC Glorioso (University of Pittsburgh) for the 7B cells and plasmid pUCX1, RE Mains (Johns Hopkins University) for the plasmid pBS.hNPY, and LA Smith (University of South Carolina School of Medicine) for technical expertise in generating the DNPY and DANPY viruses. This research was supported by: NIAAA F32AA014310 to SD Primeaux; NIMH MH59865 and MH63344 to MA Wilson; and NIDDK 32089 to George A Bray.

\section{REFERENCES}

Allen YS, Roberts GW, Bloom SR, Crow TJ, Polak JM (1984). Neuropeptide $\mathrm{Y}$ in the stria terminalis: evidence for an amygdalofugal projection. Brain Res 321: 357-362.

Bannon AW, Seda J, Carmouche M, Francis JM, Norman MH, Karbon B et al (2000). Behavioral Characterization of neuropeptide Y knockout mice. Brain Res 868: 79-87.

Baraban SC, Hollopeter G, Erickson JC, Schwartzkroin PA, Palmiter RD (1997). Knock-out mice reveal a critical antiepileptic role for neuropeptide Y. J Neurosci 17: 8927-8936.
Britton KT, Akwa Y, Spina MG, Koob GF (2000). Neuropeptide Y blocks anxiogenic-like behavioral action of corticotropin-releasing factor in an operant conflict test and elevated plus maze. Peptides 21: 37-44.

Britton KT, Southerland S, Van Uden E, Kirby D, Rivier J, Koob GF (1997). Anxiolytic activity of NPY receptor agonists in the conflict test. Psychopharmacology 132: 6-13.

Broqua P, Wettstein JG, Rocher MN, Gauthier-Martin B, Junien JL (1995). Behavioral effects of neuropeptide Y receptor agonists in the elevated plus-maze and fear potentiated startle procedures. Behav Pharmacol 6: 215-222.

Carlezon Jr WA, Haile CN, Coppersmith R, Hayashi Y, Malinow R, Neve RL et al (2000a). Distinct sites of opiate reward and aversion within the midbrain identified using a herpes simplex virus vector expressing GluR1. J Neurosci 20: RC62.

Carlezon Jr WA, Nestler EJ, Neve RL (2000b). Herpes simplex virus-mediated gene transfer as a tool for neuropsychiatric research. Crit Rev Neurobiol 14: 47-67.

Chronwall BM, DiMaggio DA, Massari VJ, Pickel VM, Ruggiero DA, O'Donohue TL (1985). The anatomy of neuropeptide-Ycontaining neurons in rat brain. Neuroscience 15: 1159-1181.

Daniels AJ, Chance WT, Grizzle MK, Heyer D, Matthews JE (2001). Food intake inhibition and reduction in body weight gain in rats treated with GI264879A, a non-selective NPY-Y1 receptor antagonist. Peptides 22: 483-491.

Davis M, Walker DL, Lee Y (1997). Amygdala and bed nucleus of the stria terminalis: differential roles in fear and anxiety measured with the acoustic startle reflex. Philos Trans $R$ Soc Lond Ser B 352: 1675-1687.

DeLuca NA, McCarthy AM, Schaffer PA (1985). Isolation and characterization of deletion mutants of herpes simplex virus type 1 in the gene encoding immediate-early regulatory protein ICP4. $J$ Virol 56: 558-570.

Erickson JC, Clegg KE, Palmiter RD (1996). Sensitivity to leptin and susceptibility to seizures of mice lacking neuropeptide $\mathrm{Y}$. Nature 381: 415-421.

Flood JF, Morley JE (1991). Increased food intake by neuropeptide $\mathrm{Y}$ is due to an increased motivation to eat. Peptides 12: $1329-1332$.

Gustafson EL, Smith KE, Durkin MM, Walker MW, Gerald C, Weinshank R et al (1997). Distribution of the neuropeptide Y Y2 receptor mRNA in rat central nervous system. Brain Res Mol Brain Res 46: 223-235.

Heilig M (1995). Antisense inhibition of neuropeptide Y (NPY)-Y1 receptor expression blocks the anxiolytic-like action of NPY in amygdala and paradoxically increases feeding. Regul Peptides 59: 201-205.

Heilig M, McLeod S, Brot M, Heinrichs SC, Menzaghi F, Koob GF et al (1993). Anxiolytic-like action of neuropeptide Y: mediation by $\mathrm{Y} 1$ receptors in amygdala and dissociation from food intake effects. Neuropsychopharmacology 8: 357-363.

Heilig M, Vecsei L, Widerlov E (1989). Opposite effects of centrally administered neuropeptide Y (NPY) on locomotor activity of spontaneously hypertensive (SH) and normal rats. Acta Physiol Scand 137: 243-248.

Heilig M, Widerlov E (1990). Neuropeptide Y: an overview of central distribution, functional aspects, and possible involvement in neuropsychiatric illnesses. Acta Psychiatr Scand 82: 95-114.

Hermens WT, Verhaagen J (1998). Viral vectors, tools for gene transfer in the nervous system. Prog Neurobiol 55: 399-432.

Holmes PV, Davis RC, Masini CV, Primeaux SD (1998). Effects of olfactory bulbectomy on neuropeptide gene expression in the rat olfactory/limbic system. Neuroscience 86: 587-596.

Inui A (1999). Feeding and body-weight regulation by hypothalamic neuropeptides - mediation of the actions of leptin. Trends Neurosci 22: 62-67. 
Jimenez-Vasquez PA, Mathe AA, Thomas JD, Riley EP, Ehlers CL (2001). Early maternal separation alters neuropeptide $Y$ concentrations in selected brain regions in adult rats. Dev Brain Res 131: 149-152.

Jimenez-Vasquez PA, Overstreet DH, Mathe AA (2000). Neuropeptide $\mathrm{Y}$ in male and female brains of flinders sensitive line, a rat model of depression. Effects of electroconvulsive stimuli. J Psychiatr Res 34: 405-412.

Kang W, Wilson MA, Bender MA, Glorioso JC, Wilson SP (1998). Herpes virus-mediated preproenkephalin gene transfer to the amygdala is antinociceptive. Brain Res 792: 133-135.

Kang W, Wilson SP, Wilson MA (2000). Overexpression of proenkephalin in the amygdala potentiates the anxiolytic effects of benzodiazepines. Neuropsychopharmacology 22: 77-88.

Kaplitt MG, Makimura H (1997). Defective viral vectors as agents for gene transfer in the nervous system. J Neurosci Methods 71: $125-132$.

Kask A, Harro J, von Horsten S, Redrobe JP, Dumont Y, Quirion R (2002). The neurocircuitry and receptor subtypes mediating anxiolytic-like effects of neuropeptide Y. Neurosci Biobehav Rev 26: 259-283.

Kask A, Kivastik T, Rago L, Harro J (1999). Neuropeptide Y Y1 receptor antagonist BIBP 3226 produces conditioned place aversion in rats. Prog Neuropsychopharmacol Biol Psychiatry 23: 705-711.

Kask A, Rago L, Harro J (1996). Anxiogenic-like effect of the neuropeptide Y Y1 receptor antagonist BIBP 3226: antagonism with diazepam. Eur J Pharmacol 317: R3-R4.

Kask A, Rago L, Harro J (1998). Anxiogenic-like effect of the NPY Y1 receptor antagonist BIBP 3226 administered into the dorsal periaqueductal gray matter in rats. Regul Peptides 75-76: 255-262.

Kay MA, Glorioso JC, Naldini L (2001). Viral vectors for gene therapy: the art of turning infectious agents into vehicles of therapeutics. Nat Med 7: 33-40.

Krisky DM, Marconi PC, Oligino T, Rouse RJ, Fink DJ, Glorioso JC (1997). Rapid method for construction of recombinant HSV gene transfer vectors. Gene Ther 4: 1120-1125.

LeDoux JE (1992). Brain mechanisms of emotion and emotional learning. Curr Opin Neurobiol 2: 191-197.

LeDoux JE (2000). Emotion circuits in the brain. Annu Rev Neurosci 23: 155-184.

MacGregor GR, Caskey CT (1989). Construction of plasmids that express E. coli beta-galactosidase in mammalian cells. Nucleic Acids Res 17: 2365.

Marconi P, Krisky D, Oligino T, Poliani PL, Ramakrishnan R, Goins WF et al (1996). Replication-defective herpes simplex virus vectors for gene transfer in vivo. Proc Natl Acad Sci USA 93: 11319-11320.

Mullins D, Kirby D, Hwa J, Guzzi M, Rivier J, Parker E (2001). Identification of potent and selective neuropeptide $\mathrm{Y} Y(1)$ receptor agonists with orexigenic activity in vivo. Mol Pharmacol 60: 534-540.

Nakajima M, Inui A, Asakawa A, Momose K, Ueno N, Teranishi A et al (1998). Neuropeptide $\mathrm{Y}$ produces anxiety via Y2-type receptors. Peptides 19: 359-363.

Palkovits M, Brownstein MJ (1988). Maps and Guide to Microdissection of the Rat Brain. Elsevier Science Publishing Co. Inc.: New York.

Parker RM, Herzog H (1999). Regional distribution of Y-receptor subtype mRNAs in rat brain. Eur J Neurosci 11: 1431-1448.

Paxinos G, Watson C (1997). The Rat Brain in Stereotaxic Coordinates. Academic Press: San Diego.

Pich EM, Agnati LF, Zini I, Marrama P, Carani C (1993). Neuropeptide Y produces anxiolytic effects in spontaneously hypertensive rats. Peptides 14: 909-912.
Polidori C, Ciccocioppo R, Regoli D, Massi M (2000). Neuropeptide $\mathrm{Y}$ receptor(s) mediating feeding in the rat: characterization with antagonists. Peptides 21: 29-35.

Primeaux SD, Holmes PV (2000). Olfactory bulbectomy increases met-enkephalin- and neuropeptide-Y-like immunoreactivity in rat limbic structures. Pharmacol Biochem Behav 67: 331-337.

Primeaux SD, Holmes PV, Martin RJ, Dean RG, Edwards GL (2000). Experimentally induced attenuation of neuropeptide-Y gene expression in transgenic mice increases mortality rate following seizures. Neurosci Lett 287: 61-64.

Primeaux SD, Wilson MA, Wilson SP, Guth AN, Lelutiu NB, Holmes PV (2003). Herpes virus-mediated preproenkephalin gene transfer in the ventral striatum mimics behavioral changes produced by olfactory bulbectomy in rats. Brain Res 988: 43-55.

Roozendaal B, Koolhaas JM, Bohus B (1997). The role of the central amygdala in stress and adaptation. Acta Psychiatr Scand Suppl 640: $51-54$.

Sajdyk TJ, Vandergriff MG, Gehlert DR (1999). Amygdalar neuropeptide Y Y1 receptors mediate the anxiolytic-like actions of neuropeptide Y in the social interaction test. Eur J Pharmacol 368: 143-147.

Song C, Earley B, Leonard BE (1996). The effects of central administration of neuropeptide $\mathrm{Y}$ on behavior, neurotransmitter, and immune functions in the olfactory bulbectomized rat model of depression. Brain Behav Immun 10: 1-16.

Stogner KA, Holmes PV (2000). Neuropeptide-Y exerts antidepressant-like effects in the forced swim test in rats. Eur $J$ Pharmacol 387: R9-10.

Taylor IL, Mannon PJ, Heintz GG, Kaiser LM, Nguyen TD (1990). Comparison of the neuropeptide $\mathrm{Y}$ receptor in the rat Brain and intestine. Ann NY Acad Sci 611: 48-57.

Vezzani A, Michalkiewicz M, Michalkiewicz T, Moneta D, Ravizza T, Richichi C et al (2002). Seizure susceptibility and epileptogenesis are decreased in transgenic rats overexpressing neuropeptide Y. Neuroscience 110: 237-243.

Wahlestedt C, PIch EM, Koob GF, Yee F, Heilig M (1993). Modulation of anxiety and neuropeptide $\mathrm{Y}-\mathrm{Y} 1$ receptors by antisense oligodeoxynucleotides. Science 259: 528-531.

Wallace KJ, Rosen JB (2001). Neurotoxic lesions of the lateral nucleus of the amygdala decrease conditioned fear but not unconditioned fear of a predator odor: comparison with electrolytic lesions. J Neurosci 21: 3619-3627.

Weinshenker D, Szot P, Miller NS, Rust NC, Hohmann JG, Pyati U et al (2001). Genetic comparison of seizure control by norepinephrine and neuropeptide Y. J Neurosci 21: 7764-7769.

Widerlov E, Lindstrom LH, Wahlestedt C, Ekman R (1988). Neuropeptide Y and Peptide YY as possible cerebrospinal fluid markers for major depression and schizophrenia, respectively. J Psychiatr Res 22: 69-79.

Wilding JP (2002). Neuropeptides and appetite control. Diabetes Med 19: 619-627.

Wolak ML, De Joseph MR, Cator AD, Mokashi AS, Brownfield MS, Urban JH (2003). Comparative distribution of neuropeptide $Y$ Y1 and Y5 receptors in the rat brain by using immunohistochemistry. J Comp Neurol 464: 285-311.

Woldbye DP, Larsen PJ, Mikkelsen JD, Klemp K, Madsen TM, Bolwig TG (1997). Powerful inhibition of kainic acid seizures by neuropeptide Y via Y5-like receptors. Nat Med 3: 761-764.

Woldbye DP, Madsen TM, Larsen PJ, Mikkelsen JD, Bolwig TG (1996). Neuropeptide Y inhibits hippocampal seizures and wet dog shakes. Brain Res 737: 162-168.

Zardetto-Smith AM, Gray TS (1990). Organization of peptidergic and catecholaminergic efferents from the nucleus of the solitary tract to the rat amygdala. Brain Res Bull 25: 875-887. 